\title{
Chinese Traditional Folk Pattern and Modern Graphic Design
}

\author{
Jun Gong \\ College of Art and Appareluages, Tianjin Polytechnic University, Tianjin 300160, China \\ E-mail: gongong1982@126.com
}

\begin{abstract}
Traditional Chinese folk graphics has been the rich cultural heritage of the nation, which provided a wealth of design elements for the modern graphic design. Modern graphic design blends with traditional Chinese folk patterns to give them new characteristics of the times, not only represents the traditional culture and innovation, but also indicates that China's graphic design is entering a new stage of development at the international level, to show the unique spirit of oriental culture.
\end{abstract}

Keywords: Folk pattern, Traditional culture, Visual symbol, Graphic design

Any country and nation in the world form her unique custom during the long process of reproduction and development, as well as various folk art forms. These art forms are created by the working people directly, which are the valuable asset for generations. The art shows the emotion of love life and the pursuit of happiness. Until now, although the folk art has experienced rapid times change, it still remained the spectacular style. After the innovation by modern artists, it has reached a new height of development with new value in new era.

\section{Chinese Traditional Folk Pattern}

Traditional Chinese folk pattern is an important part and expression of folk art, with profound connotation and spiritual essence for 5,000 years. The characters of it is, rich content, meaning and forms with long history. It implies on the auspicious and rhythm of life, not for the pursuit of the natural image, but for the visual symbols or graphics of traditional life. Traditional folk pattern played an important role of showing the folk ideological outlook, therefore, several of visual folk art style depends on the spirit and visual of transmission by folk patterns.

\subsection{Spiritual meaning}

Folk graphic is linked to people subjective feeling with the results of historical accumulation. Chinese people always like to seek lucky by the means of art forms. As a result, the subject of folk graphic usually focus on "Blessing, Rich and Long life", "harmony" and "happiness and wealth" reflecting the eternal survival needs and the good wishes of avoiding disaster. Therefore, the traditional Chinese folk graphic can also be considered as keepsake of lucky and happiness, which makes role in people's subconsciousness. As a concept of visual symbols, folk graphic presents unique social and cultural phenomena in the sense of nation psychology.

\subsection{Expression method}

The significances of traditional Chinese folk patterns are often full of meaning by idealized image to break the limitations of time and space. Different seasons and different places can also appear in the same pattern, not conveying the concept of the thing itself, but in the metaphor by the subjective ideas and aspirations. That is to say, folk patterns convey the ideas by the mean of pun, implying, symbol and metaphor, by dint of some image character and semantic homonym, for example, pairs of mandarin ducks means the love of spouse, and "fish" and "balance" has semantic homonym in Chinese pronunciation means happiness year by year. (Figure 1-2).

\subsection{Expression content}

On the impact of Confucianism, Chinese people believed the harmony of god and human in the nature. Chinese peoples is the one of who created the patterns of landscapes, flowers and birds, therefore, the traditional Chinese folk patterns appeared in a large number of flowers, birds, insects, fish, animals and other natural things by empowering them to enrich various auspicious connotation, for example, dragon, phoenix and unicorn are the guardian of animals; Bamboo, peonies, carp and magpies are a symbol of wealth and safety (Figure 3-4). These above expression reflect the natural concept of harmony, as well as the taste intent of advocating natural aesthetic.

In China's traditional concept, there is a aesthetic philosophy as "The truth is perfect, the beauty is real", and the meaning of "truth" here doesn't mean the visual, but the psychological truth. With the psychological demands, many brave persons, gods, auspicious dolls and lady figures were created to express the truth and beauty as the other expression content. (Figure 5-6). Not only because they have the ability of blessing common people, restraining evil, 
and propagating life, but more importantly because their characters have the model effect of people's moral ideal. It can inspire the vivid art image and guides people to kindness, self -building, being helpful. This meaning of "beauty" here certainly reveals the direct pursuit of ideals.

Another folk pattern is a simplified visual symbol by abstracting and evolving from the auspicious Chinese characters and simple geometric shapes (Figure 7-8), which are abstract understanding about ancient material world. The implication of such profound graphics includes Oriental philosophy ideas, for example, the million words stripes possibly originated from the primitive man's worship of the sun and fire, and later applied to Buddhism, which means the lucky appearance of the Buddha and "million” times of fortune with widely favor. It is widely used in weaving, dyeing, and embroidery, paper cutting and other forms of folk art.

\section{4 cognitive forms}

With the frequent contacts and cultural exchanges, many folk graphics have evolved to the common cognitive information symbol. They have developed to perfect art forms through constantly revising and improving. This process determined folk patterns must be the common expression of one region, one nation, even one country, For example: during the Chinese New Year, every household displays the word blessing, couplets, hanging money, window paper-cuttings, which contain auspicious words to pray for safety. These patterns are full of people's good wishes of the Chinese culture. For Chinese people, they consider Lunar New Year as the biggest traditional festival, on the theme of the New Year; they created various of folk art to express the common ideal of beliefs, ideological and aesthetic temperament.

\section{Back to tradition}

In the rapid development of the market economy era, the traditional Chinese folk patterns are still showing a rise situation, with modern civilization impacting. Under the style of internationalism, although folk patterns are lack of development, folk artistic charm shine will not be lost, after all, it carries forward the Chinese people for thousands of years of cultural tradition and ways of thinking. Respect to the traditional culture, society has formed a phenomenon of cultural return, which reflected in people's daily life in every respect, as the necessary part of people's lifestyle, art style and taste. Literature, film, architecture, fashion design and graphic design, all show the traditional twist. As the typical form, traditional folk art patterns have been used in all types of graphic design, with the new characteristics of the times.

\section{Design advantage}

Folk patterns provide a wealth of design elements and semantic content for the modern graphic design. Chinese traditional folk designs have character of brief description, such as, the relation with point, line and surface elements, especially a sense of form and order in composing. Folk patterns are adept at utilizing graphic symbol to express intentions as modern design, for example, in the folk patterns, a Lotus and carp represent "successive years of surplus." pomegranate represents "having many descendants", vases symbol of peace, That auspicious with the bat, etc. Other abstract graphics, such as the Wan character, Shou character, tai chi, also contain profound significance and meaning. Therefore, these graphics are used to refer to China's traditional culture by modern designers. It is a powerful means that combine the folk pattern and modern design.

The audiences of folk patterns are the whole nation with broad approval. Folk patterns are rooted in Chinese traditional culture with profound humanistic characteristics and folklore related to people's life. To the Chinese people, the symbolic meaning of folk patterns is so specific that hard to be replaced. It is usually easy for people to understand the folk patterns' content. Taking packaging design as an example, many designers use the "magpie”, "Carp” symbolic graphics to meet the Chinese people's aesthetic psychology for cultural agreement, as well as the "knot", "Lions" images are used in posters. As a specific kind of language used in modern graphic design, folk art patterns show an obvious edge.

\section{Heritage and innovation}

Modern graphic design emphasizes on visual conveying. Designers study the Chinese traditional folk designs from the perspective of modern graphic design that is the inheritance and innovation of traditional culture. Based on the elements of folk patterns, they try to combine them with modern graphic design, to find the possibility of the best integration of traditional culture and modern civilization.

By impact of the traditional culture, many Chinese enterprises logos have the internal auspicious meaning. There are many successful logo design directly or indirectly referenced from folk patterns with reconstruction and innovation. These designs have both traditional and modern flavor. For example, logo of Far East Square is the image of Lion played with ball, to show the spirit of the combination of tradition and modern (Figure 9); the logo of Phoenix Satellite TV uses two Chinese auspicious birds "Phoenix" as the main graphics, and the circular composition form means endless sustainable enterprise spirit(Figure 10). These outstanding works of traditional visual symbols is not a simple extraction, but an upgrading of design concept, and a development of national culture and inspirit. As a design resource, 
folk pattern provides for the designers endless source for imagination and creativity. Application of modern design practices on folk pictorial innovation, it will enhance the combination of traditional and modern graphic design.

\section{Future development}

China is at an unprecedented pacing into the trend of globalization. How to develop Chinese design in the global and build self image? It has become an urgent practical problem. This is not just challenge, but opportunity for the exploration of Chinese design. Therefore, in the graphic design, it's necessary to study the language of folk art to and improve the design.

Folk pattern is rich in visual manifestations with profoundly symbolic implication that people built up common visual symbols in their daily lives. In the nation, folk pattern has a broad understanding, and becomes the Chinese culture and traditional lifestyles psychological representation. In the integration of modern graphic design and traditional Chinese folk patterns, designers must give them new characteristics of the times to show the unique spirit of the oriental culture at the international level.

\section{Summary}

With absorption of international expression means, China art designers constantly look for the ethnic characteristics of the visual symbols, to establish the Chinese language design and visual image with national character. Traditional Chinese folk patterns have become an effective display with Chinese characteristics, an important element in the design style by their rich content and relevance of social life, as well as product powerful visual resources for modern graphic design. It not only represents a form of folk art heritage and self-innovation, but also indicates that Chinese graphic design has entered a new stage of development.

\section{References}

Li, Yanzu. (2005). Graphic Design Art. Lo Ying Chinese People's University Press

Liu, Lin \& Zhao, quanyi. (2005). Auspicious New Visual Design. Wuhan University Press.

Tang, jialu. (2004). Auspicious Decoration. Lei Sun Guangxi Art Publish. China.

Yang, Xueqin. (2005). An Introduction to Folk Art. The Chinese People's University Press.

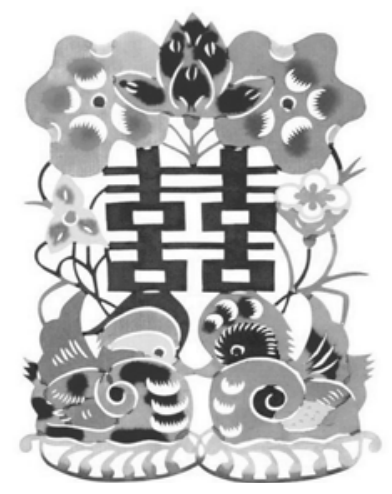

Figure 1. Paper cutting, "Mandarin

Ducks under Water Lily”

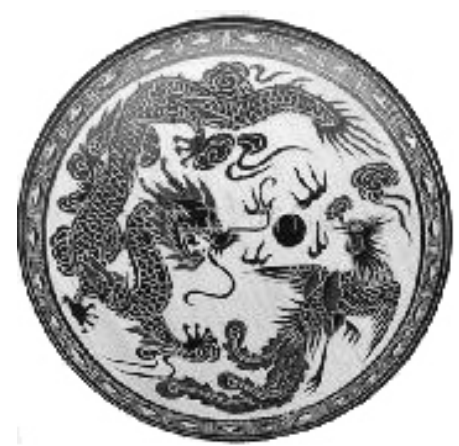

Figure 3. Woodcut, "Dragon and Phoenix"

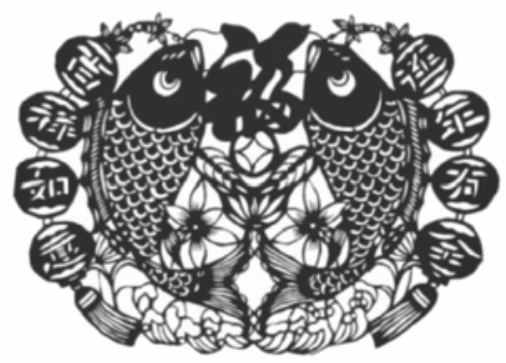

Figure 2. Paper cutting, “double fish”

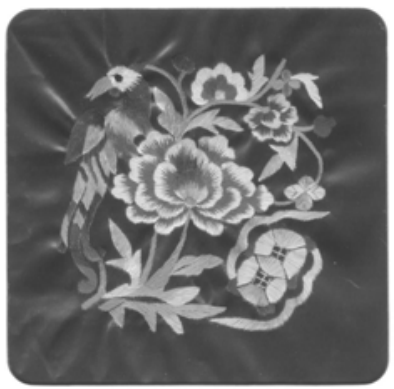

Figure 4. Embroidery, "Bloom with Wealth" 


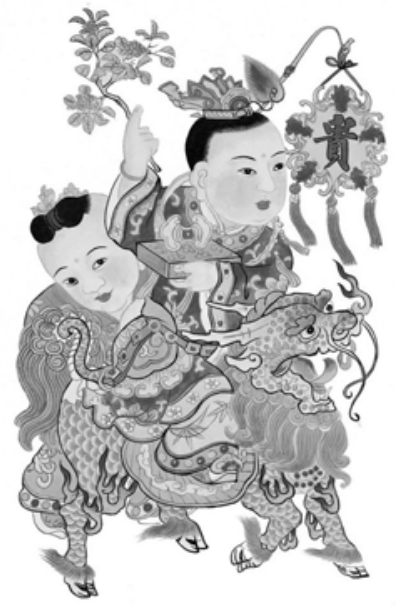

Figure 5. Lunar New Year picture "Kylin with Children"

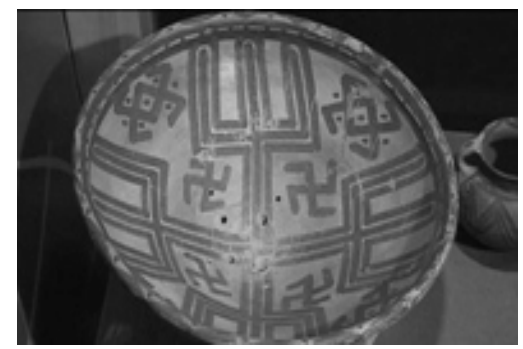

Figure 7. Plate of million words

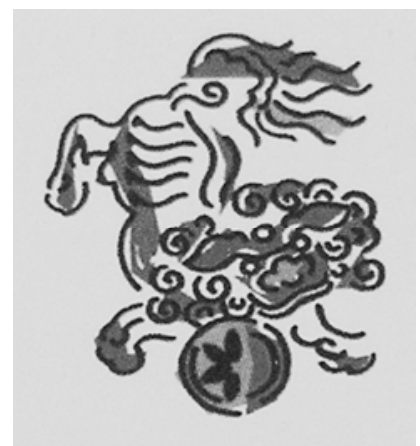

Figure 9. Logo of Far East Square

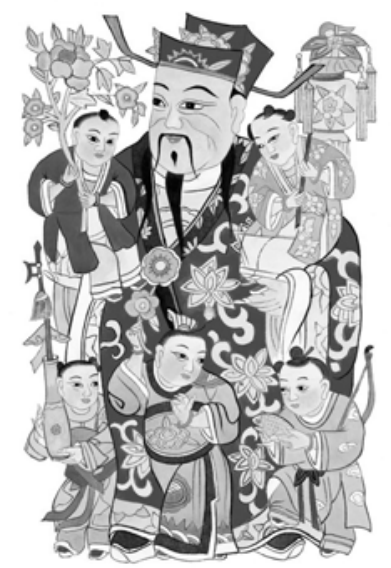

Figure 6.Lunar new year picture "Mammon"

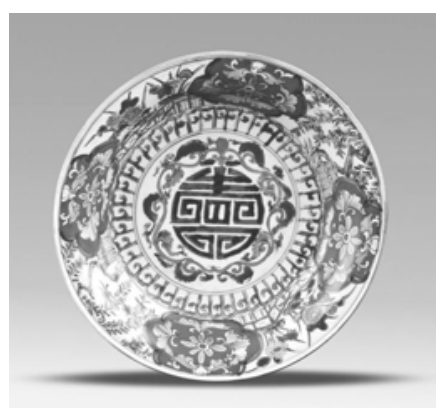

Figure 8. Plate of longevity

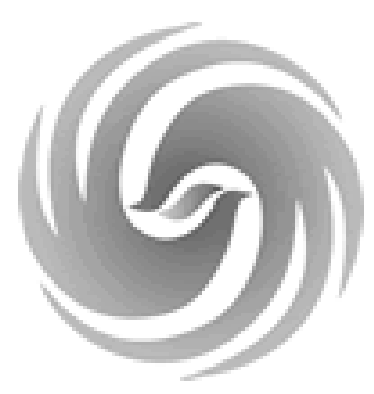

Figure 10. The logo of Phoenix Satellite TV 